\title{
Demonstration of the Adrenergic Nerves in the Rat Gastric Mucosa
}

\section{-A Histofluorescence and Electron Microscopic Study in Comparison with the Distribution of the Cholinergic Nerves--}

\author{
By \\ Masahiko NAKAMURA, Norihito WATANABE, Nobuhiro TSUKADA, \\ Masaya ODA and Masaharu TSUCHIYA \\ Department of Internal Medicine, Keio University School of Medicine, \\ Shinanomachi, Shinjuku, Tokyo 160, Japan \\ -Received for Publication, March 20, 1982-
}

\begin{abstract}
Key words: Autonomic nervous system, Rat gastric mucosa, Adrenergic nerve, Cholinergic nerve, Gastric mucosal microcirculation.

Summary: In the present study, the adrenergic nervous system in the gastric mucosa of the rat glandular stomach was reevaluated in comparison with the distribution of the cholinergic nerves by histofluorescence and electron microscopy. The "dual" nerves comprizing both cholinergic and adrenergic nerve axons were found to exist predominantly in the basal two-thirds of the fundic mucosal layer. The distribution of the adrenergic nerves, however, was scarce as compared with that of the cholinergic nerves. Both nerve fibers terminate more frequently on the true capillaries than on the epithelial cells of the fundic gland, suggesting that the gastric mucosal microcirculation is more intensely influenced by the autonomic nervous system than the gastric secretion.
\end{abstract}

The stomach is known to be very sensitive to various types of autonomic nervous stimulation, which contributes to the stress-induced ulcer formation. It has been generally accepted that the autonomic nervous system in the stomach is mainly composed of the parasympathetic (cholinergic) nerves and sympathetic (adrenergic) nerves. ${ }^{18)}$ During the past decade, great attention has been focused on the third component of the autonomic nervous system, i.e. the purinergic nerves." This nervous system is thought to have the non-cholinergic inhibitory function in the intestinal tract, instead of the adrenergic nervous system. In this respect, the sympathetic innervation in the stomach tends to be considered less important in the autonomic nervous regulation. On the other hand, however, some reports have shown abundant distribution of the adrenergic nerve fibers in the intramural nerve plexuses and around the arteries in the gastric wall. ${ }^{16)}$

Hence, the present study was designed to reevaluate the distribution of the sym- 
pathetic nerve fibers in the gastric mucosa of the rat glandular stomach by histofluorescence and electron microscopy in comparison with the distribution of the cholinergic nerves.

\section{Materials and Methods}

Wistar strain rats weighing 200-250 g were used in the experiment. Fifteen rats were divided into the following three groups: the nialamide and L-Dopa-treated group, 6-hydroxydopamine (6-OHDA)treated group and the control group. In the first group, $500 \mathrm{mg} / \mathrm{kg}$ of nialamide was administered intraperitoneally and $100 \mathrm{mg} / \mathrm{kg}$ of L-Dopa was administered intraperitoneally two hours after nialamide injection and 1 hour before sacrifice. In the second group, $20 \mathrm{mg} / \mathrm{kg}$ of $6-O H D A$ was administered per os four times every 12 hours before sacrifice.

\section{Procedures for histofluorescence microscopy}

The ALFA method," aluminium-formaldehyde perfusion method, was used for identifying the localization of noradrenaline. Under light anesthesia with intraperitoneal injection of sodium pentobarbital (Nembutal: $30 \mathrm{mg} / \mathrm{kg}$ ), the rats were perfused via a polyethylene catheter with a pressure of $20 \mathrm{~cm} \mathrm{H}_{2} \mathrm{O}$, inserted into the abdominal aorta, with $60 \mathrm{ml}$ of ice cold solution containing $2 \%$ glyoxylic acid in normal strength of Tyrode buffer and then with $40 \mathrm{ml}$ of $5 \%$ aluminium phosphate in the same buffer ( $\mathrm{pH}$ 3.8). The small tissue blocks of the stomach were freezed with isopentane quenched in liquid nitrogen, and freeze-dried at $-40^{\circ} \mathrm{C}$ and $10^{-1}$ Torr for 2 days in a vacuum freezedryer (Oka science OTD-1SF). Thereafter, they were treated with formalin gas evaporated from paraformaldehyde $(10 \mathrm{~g} / \mathrm{L})$ at $60^{\circ} \mathrm{C}$ for 1.5 hours and embedded in paraffine. Ten-micron sections were examined in a fluorescence microscope (Olympus $\mathrm{BH}$ type).

2. Procedures for electron microscopy The animals in the three groups described above were sacrificed by decapitation. The fundic portions of the rat glandular stomachs were cut into small tissue blocks (approximately $1 \times 1 \times 1 \mathrm{~mm}^{3}$ ), followed by immersion fixation with a mixed solution of $4 \%$ formaldehyde and $1 \%$ glutaraldehyde (0.06 M phosphate buffer, $\mathrm{pH} 7.4$ ) for two hours. They were post-fixed with $1 \%$ osmic acid for 2 hours at $4^{\circ} \mathrm{C}$, dehydrated in graded ethanol solutions, and embedded in "Epok 812" resin. Ultrathin sections were cut with a glass knife in a LKB ultramicrotome. Four blocks were chosen randomly from each rat. For morphometric analysis the sections from each block were examined at low magnification and one grid square view of DN300 mesh $\left(45 \times 45 \mu^{2}\right)$, mainly containing the chief, parietal, and mucous neck cells, was chosen from each section: totally 60 grid squares were observed. The number of all the terminal and non-terminal axons, epithelial and endothelial cells were counted in each square. The nerve profiles were classified into 9 classes as described in the results, according to the kinds of the synaptic vesicles contained in the nerve varicosities and the types of the adjacent cells such as the capillary endothelium, glandular epithelium and preterminal axon, apart from the effectors. The axons containing both adrenergic and cholinergic nerve fibers were referred to as "dual" for clarifying its significance.

\section{Results}

\section{Fluorescence microscopic observation}

A. The control group

The bluish green fluorescence in the preparations processed by the ALFA method, indicating the presence of noradrenaline, was seen mainly in the perivascular plexuses surrounding the ar- 
Table 1. Morphometric analyses on distribution of the autonomic nerves in the rat gastric mucosal layer.

\begin{tabular}{|c|c|c|c|c|c|}
\hline \multirow{2}{*}{$\begin{array}{l}\text { gastric mucosal } \\
\text { layer zone }\end{array}$} & \multirow{2}{*}{$\begin{array}{l}\text { classification of the } \\
\text { autonomic nerves }\end{array}$} & \multirow{2}{*}{$\begin{array}{l}\text { number } / 45 \times 45 \mu^{2} \\
(\text { mean } \pm S D)\end{array}$} & \multicolumn{3}{|c|}{ localization of the nerves (mean $\pm S D$ ) } \\
\hline & & & $\begin{array}{l}\text { perimicrovascular } \\
\text { portion }\end{array}$ & $\begin{array}{l}\text { periepithelial } \\
\text { portion }\end{array}$ & $\begin{array}{l}\text { intermediate } \\
\text { portion }\end{array}$ \\
\hline \multirow{4}{*}{$\begin{array}{l}\text { lower zone } \\
(n=20)\end{array}$} & adrenergic & $0 \pm 0$ & $0 \pm 0$ & $0 \pm 0$ & $0 \pm 0$ \\
\hline & adrenergic +chol inergic & $0.4 \pm 0.6$ & $0.05 \pm 0.22$ & $0.1 \pm 0.31$ & $0.25 \pm 0.55$ \\
\hline & cholinergic & $1.2 \pm 0.77$ & $0.65 \pm 0.67$ & $0.4 \pm 0.5$ & $0.25 \pm 0.55$ \\
\hline & total & $1.6 \pm 0.88$ & $0.70 \pm 0.73$ & $0.5 \pm 0.61$ & $0.5 \pm 0.87$ \\
\hline \multirow{5}{*}{$\begin{array}{l}\text { middle zone } \\
\quad(n=20)\end{array}$} & adrenergic & $0.1 \pm 0.31$ & $0.05 \pm 0.23$ & $0.05 \pm 0.23$ & $0 \pm 0$ \\
\hline & adrenergic + cholinergic & $0.55 \pm 0.61$ & $0.25 \pm 0.44$ & $0.25 \pm 0.44$ & $0.05 \pm 0.23$ \\
\hline & $\begin{array}{l}\text { adrenergict } \\
\text { (adrenergictcholinergic) }\end{array}$ & $0.65 \pm 0.67$ & $0.3 \pm 0.47$ & $0.3 \pm 0.47$ & $0.05 \pm 0.23$ \\
\hline & cholinergic & $2.1 \pm 1.2$ & $1.2 \pm 0.83$ & $0.65 \pm 0.88$ & $0.25 \pm 0.55$ \\
\hline & total & $2.75 \pm 1.48$ & $1.5 \pm 0.89$ & $0.95 \pm 1.1$ & $0.3 \pm 0.57$ \\
\hline \multirow{4}{*}{$\begin{array}{l}\text { upper zone } \\
\quad(n=20)\end{array}$} & adrenergic & $0 \pm 0$ & $0 \pm 0$ & $0 \pm 0$ & $0 \pm 0$ \\
\hline & adrenergic +cholinergic & $0.2 \pm 0.41$ & $0.1 \pm 0.31$ & $0 \pm 0$ & $0.1 \pm 0.31$ \\
\hline & cholinergic & $1.15 \pm 0.88$ & $0.75 \pm 0.64$ & $0.4 \pm 0.5$ & $0 \pm 0$ \\
\hline & total & $1.35 \pm 0.81$ & $0.85 \pm 0.59$ & $0.4 \pm 0.5$ & $0.1 \pm 0.31$ \\
\hline
\end{tabular}

terioles and the metarterioles and some between the fundic epithelial cells in the mucosal layer of the glandular stomach in the control rat (Fig. 6). These fluorescent fibers correspond to the adrenergic (sympathetic) nerve fibers.

B. The nialamide and L-Dopa-treated group

In the nialamide and L-Dopa-treated group, many fine varicose fluorescent fibers stained bluish-green were present between the gastric epithelial cells in the lamina propria mucosae of the lower one-third of the rat fundic gland (Fig. 7). Some of these fluorescent fibers were closely associated with the capillaries. A part of the epithelial cells were also fluorescent. Most of these fluorescent cells correspond to the granulated cells located at the basal sites of the fundic gland, which were most likely to be the enterochro- maffin-like cells (ECL cells). In the middle and the upper two-thirds of the fundic gland, some of the fluorescent nerve fibers were also observed between the gastric epithelial cells (Fig. 9, 10).

C. The 6-OHDA-treated group

In the 6-OHDA-treated group, the specific fluorescence entirely disappeared (Fig. 8). The non-specific dotted fluorescence remained only in the chief cells.

\section{Electron microscopic observation}

A. Distribution and structure of the nerves at electron microscopic level

Most of the nerve axons and their varicosities were seen in parallel with the endothelium of the capillary (Fig. 11). The nerve fibers were unmyelinated in the gastric mucosal layer and partly or totally surrounded with Schwann cells. Some of the varicosities were occasionally 
found to be closely associated with the capillary endothelial cells and the glandular epithelial cells (Fig. 12, 15, 16, 17). There were only a few axons near the non-vascular smooth muscle cells in the lower one-third of the fundic gland (Fig. 14).

\section{B. Types of the nerves}

Electron microscopic observation revealed three types of the nerves in the gastric mucosal layer: the cholinergic, adrenergic and purinergic or peptidergic nerves. The synaptic vesicles in these three types of nerve endings were characterized respectively by the small and clear vesicles $(45-60 \mathrm{~nm}$ in diameter), the small and granulated vesicles $(40-50 \mathrm{~nm}$ in diameter) and the large and electron opaque vesicles $(150-200 \mathrm{~nm}$ in diameter). As shown in Fig. 18, the purinergic nerves were so rare that the morphometric analyses by electron microscopy were made only as to the distribution of the cholinergic and adrenergic nerves as described below. In the 6-OHDA-administered rats, the adrenergic axons were selectively degenerated in the unmyelinated nerve endings (Fig. 12), and some of the endothelial junctions were widely opened (Fig. 13).
3. Morphometric analyses on the autonomic nervous distribution in the gastric mucosal layer by electron microscopy

A. Differences in distribution between the cholinergic and the adrenergic nerves in three different zones of the gastric mucosal layer (Fig. 1).

Throughout the gastric mucosal layer, the cholinergic nerves were predominant as compared with the adrenergic nerves. The "mixed form", consisting of both adrenergic and cholinergic nerve axons, were occasionally found at the middle or basal sites of the gastric mucosal layer. The ratio of the number of the cholinergic nerve to that of the adrenergic nerves was $3.09,2.90$ and 8.00 , respectively, indicating that the cholinergic nerves were much more numerous in the upper zone than the adrenergic.

B. Distribution of the cholinergic and adrenergic nerves in each gastric mucosal zone (Fig. 2).

In the total number of the autonomic nerves, the nervous distribution was significantly abundant in the middle zone. The adrenergic nerves were scarcely found in the upper zone. Dual nerves were significantly rarer in the upper zone

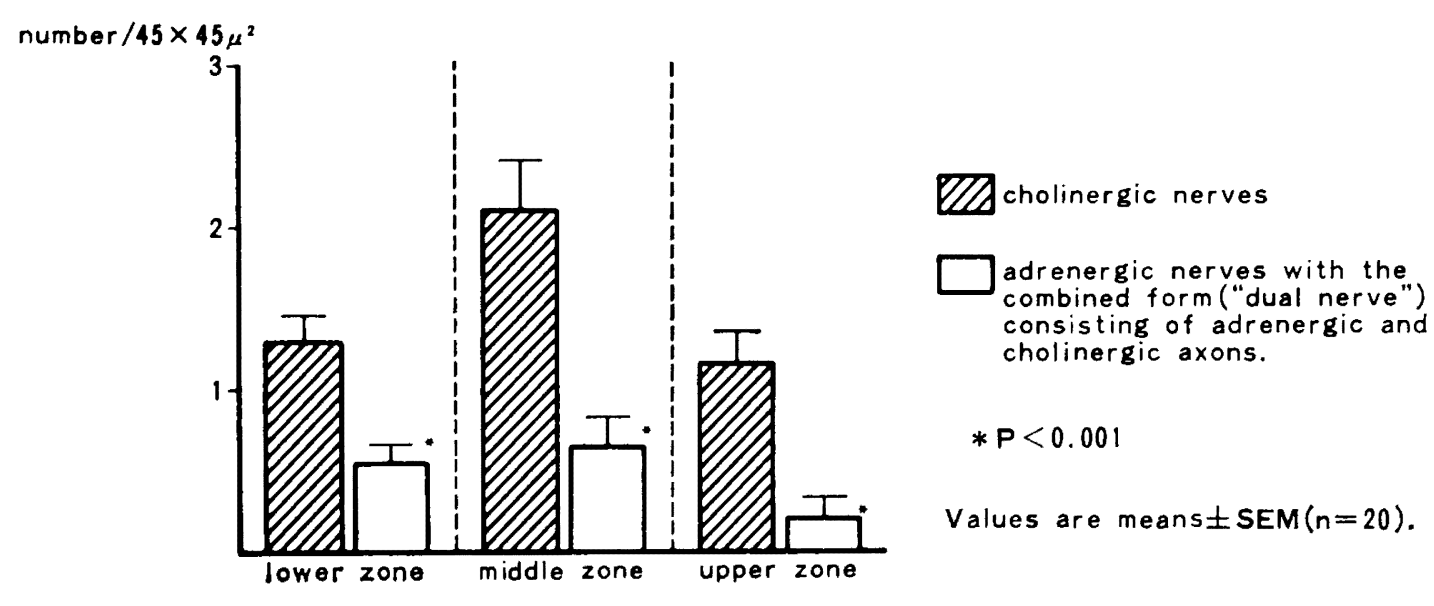

gastric mucosal layer

Fig. 1. Distribution of the cholinergic and adrenergic nerves in each gastric mucosal zone. 


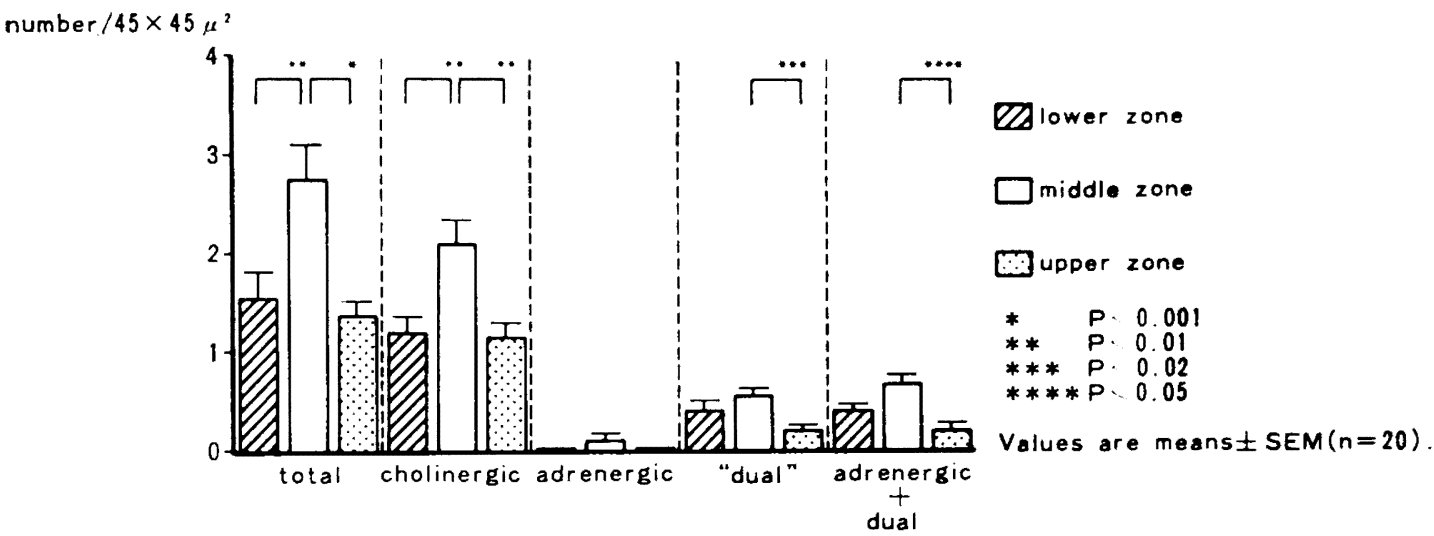

Fig. 2. Differences in distribution pattern of three types of the nerve endings in three different zones of the gastric mucosal layer.

than in the other two zones.

C. Distribution pattern and effectors of three types of nerves in each gastric mucosal zone (Fig. 3).

The number of the nerves closely associated with the true capillary endothelium or with the epithelium of the rat fundic gland at a distance less than 100 $\mathrm{nm}$ was calculated. The other nerves were classified into an "intermediate" type. In the middle and upper zone, the nerve endings located near the endothelium were numerous. Many of them were cholinergic, based on the ultrastructure of the nerve endings.

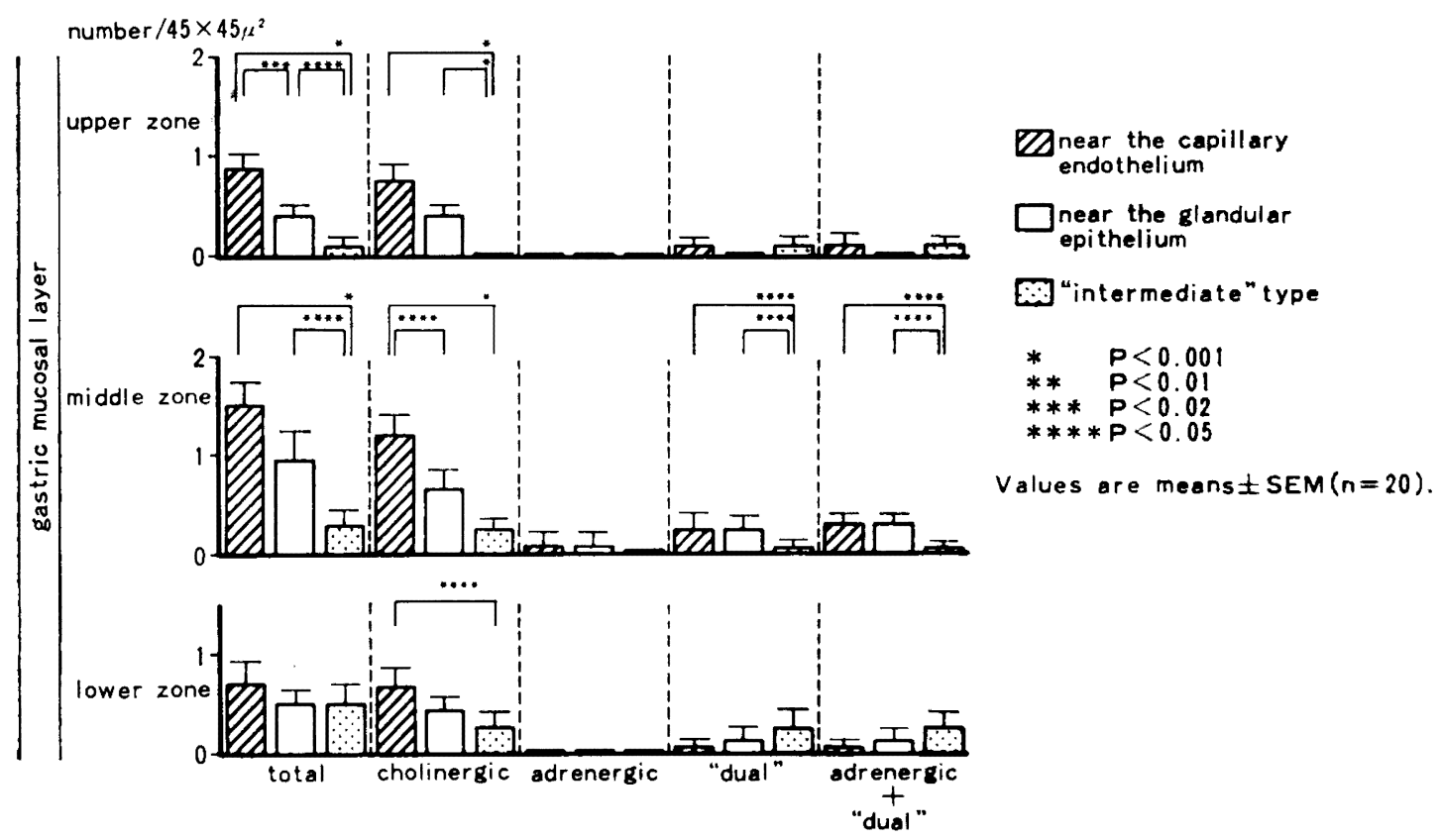

Fig. 3. Distribution pattern and effectors of three types of the nerve endings in each gastric mucosal zone. 
D. Differences in distribution pattern and effectors of three types of the nerve endings in three zones of the gastric mucosal layer (Fig. 4).

The close relation between the unmye- linated nerve endings, both cholinergic and adrenergic, and the capillary endothelium, was designated as "innervated" endothelium, and was most frequently observed in the middle zone. The nerve

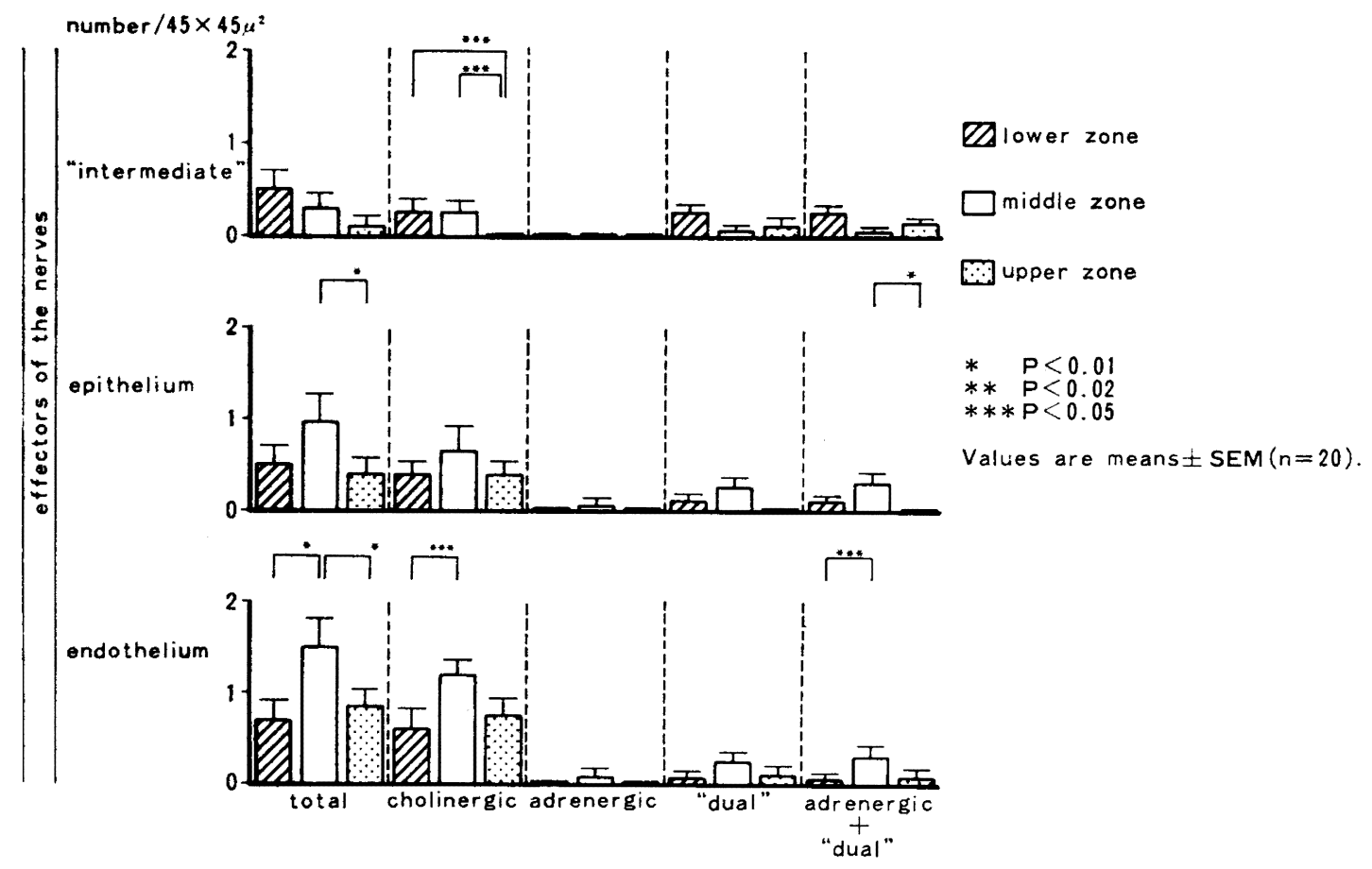

Fig. 4. Differences in distribution pattern and effectors of the nerve endings in three different zones of the gastric mucosal layer.

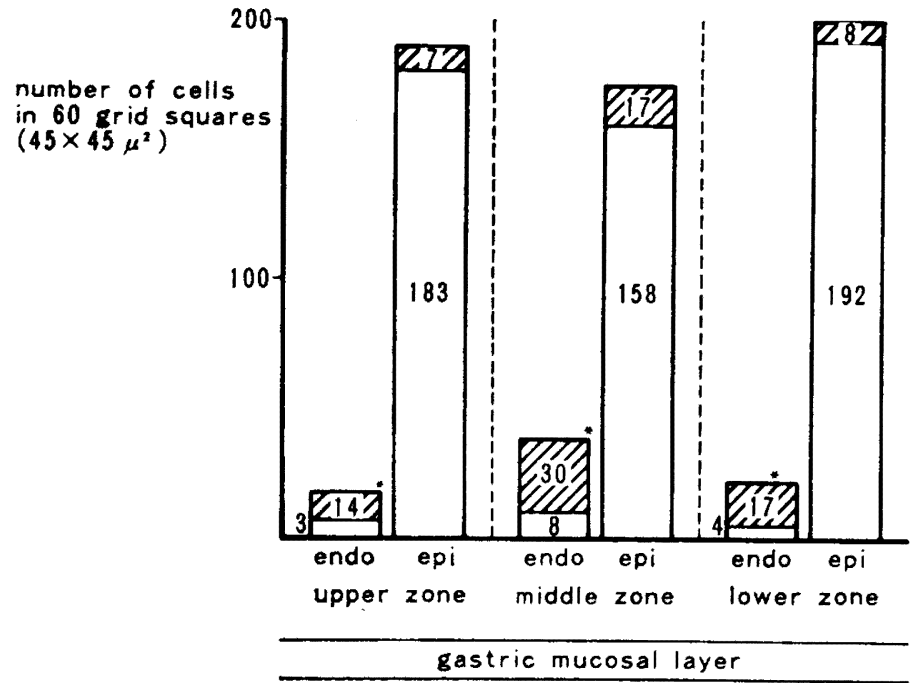
QInnervated" endothelium
or epithelium
$\square$ "non-innervated" endothelium
or epithelium $* P<0.005$ (by $\chi^{2}$ test)
endo: endothelium
epi : epithelium

Fig. 5. The ratio of "innervated" capillary endothelium or glandular epithelium to "non-innervated" in each gastric mucosal zone. 
endings closely associated with the glandular epithelial cells were also the most numerous in the middle zone, as compared with the number of such nerve endings in the other two zones. The close relation between the nerve endings and the epithelium was designated as "innervated" epithelium. The endothelium or the epithelium without the nerve endings was called "non-innervated".

E. The ratio of the number of "innervated" capillary endothelium or glandular epithelium to that of "non-innervated" in each gastric mucosal zone.

As shown in Fig. 5, it was statistically significant that the nerve endings were more abundant near the capillary endothelium than near the glandular epithelium in each gastric mucosal zone.

\section{Discussion}

Mainly from physiological point of view, the gastrointestinal tract, especially the gastric mucosa is thought to be innervated with the vagal nerve and its associated enteric nervous system. ${ }^{9), 13), 15)}$ This concept is strongly supported by the present ultrastructural study. The intimate relation between the cholinergic nerve endings and the glandular epithelial cells implies a direct cholinergic innervation of the epithelium such as the parietal cell. On the other hand, the sympathetic nerves may also play a certain role in the regulation of the gastric mucosal function.

Recently much progress has been made in the identification of the adrenergic nerves at light microscopic level by using the histofluorescence method originally reported by Falck and Hillarp. ${ }^{8)}$ For identifying the precise localization of the biogenic amines at ultrastructural level, it is necessary to improve the conventional electron microscopic techniques, because most of the biogenic amines are washed away during the fixation and dehydration process for electron microscopy. ${ }^{b}$ However, 6-hydroxydopamine (6-OHDA), a potent drug for chemical sympathectomy, is able to selectively degenerate the sympathetic nerve endings. ${ }^{14}$. As has been proved in this study, 6-OHDA treatment is very useful to electron microscopically determine the presence of the adrenergic nerve axons on the basis of the degenerative findings of the nerve endings even in the preparations processed by a conventional electron microscopic procedure.

There are two main hypotheses currently proposed concerning the distribution of the sympathetic nerves in the gastrointestinal tract. One implies that the sympathetic nervous system is of minor importance, only innervating the circular smooth muscle, and an inhibitory control against the parasympathetic nervous system is mainly made by the purinergic nervous system." The sympathetic nerves are thought to show an indirect inhibitory function via the intramural parasympathetic ganglion. The other is that the sympathetic nerves are widely distributed in the gastrointestinal tract, and are involved in the regulatory mechanism of a variety of gastrointestinal function. ${ }^{5), 16)}$

The present study revealed that most of the sympathetic and parasympathetic nerve endings in the fundic portion of the rat glandular stomach are closely associated with the blood microvessel walls and some are associated with the glandular epithelial cells. For determining more precisely the "innervated" endothelium and epithelium, it is necessary to observe the surface area of these two types of cells by scanning electron microscopy using $\mathrm{HCl}$-collagenase digestion technique. ${ }^{11), 16)}$

In general, the distance between the presynaptic and postsynaptic membrane is important in the formation of the neuro- 
synaptic junction. In this study, the distance between the autonomic nerve endings and the endothelium or epithelium in the gastric mucosa was largely less than $100 \mathrm{~nm}$. Therefore, this type of the junction is found to be more similar to the neuromuscular junction in vascular smooth muscles with a synaptic cleft distance of approximately 100-300 nm than that in visceral smooth muscles with a synaptic cleft distance of $2-30 \mathrm{~nm}^{2}{ }^{2), 12}$ )

As to the innervation of the vascular system, the sympathetic nerve fibers were shown around the capillary vessels in the white adipose tissue ${ }^{18)}$ by a histofluorescence technique. The dual, cholinergic and adrenergic, innervation of the arteries and arterioles in the epididymis ${ }^{7}$ was also reported. The adrenergic fibers represent postganglionic sympathetic vasoconstrictor nerves, and the cholinergic nerve fibers an antagonistic vasodilator nerve as far as a histochemical study is concerned. As shown in the present study, the dual innervated capillaries are observed in the mucosal layer of the rat stomach. The close proximity between the adrenergic and cholinergic varicosities leads us to speculate on the above-mentioned presynaptic modulation of neurotransmitter relase, originally demonstrated by Burn and Rand. ${ }^{\text {s) }}$ A presynaptic modulation of acetylcholine release by noradrenaline or a modification of noradrenaline output from the adrenergic nerves by acetylcholine has been evidenced by a pharmacological study. ${ }^{11}$ The present morphological findings would support such cholinergic and adrenergic interactions in the gastric mucosa, explaining the gastric mucosal fragility to various autonomic nervous irritations. The opening of the capillary endothelial junction induced by 6-OHDA administration, leading to the various disturbances of the gastric mucosal microcirculation, is one of the evidences for supporting this hypothesis.

In the fundic gland of the L-Dopa administered rat, a large number of epithelial cells showed the strong yellow fluorescence, indicating these cells coincide with enterochromaffin-like (ECL) cells. ${ }^{10)}$ The relation between the ECL cells and the autonomic nerves remains to be further elucidated, since these cells are considered to be important as a source of histamine in the gastric mucosal layer. 6-OHDA administration resulted in the complete disappearence of the bluish-green, linear fluorescence, proving that the fluorescence is specific for the biogenic amines, especially for noradrenaline.

The parietal cell area in the gastric mucosal layer is most enriched in the distribution of the autonomic nerves, reflecting that this area is very active in the tissue metabolism such as acid secretion and circulatory modulation.

\section{Acknowledgement}

We would like to express our thanks to Prof. Kazuyo Shimai and Assist. Prof. Koji Kami, Department of Anatomy, Keio University Sohool of Medicine for their precious advices.

This work was supported by a grant in Aid for scientific research from the Ministry of Education, Science and Culture of Japan ( $\$ 56107005)$.

\section{References}

1) Ajelis, V., Björklund, A., Faick, B., Lindvall, O., Loren, I. \& Walles, B.: Application of aluminium-formaldehyde (ALFA) histofluorescence method for demonstration of peripheral stores of catecolamine and indolamines in freeze-dried paraffine embedded tissue, cryostat sections and whole mounts. Histochemistry, 6: 1-15, 1979.

2) Bell, C.: Fine structural localization of acetylcholinesterase at a cholinergic vaso- 
dilator nerve-arterial smooth muscle synapse. Circ. Res., 24 : 61-70, 1969.

3) Burn, J.H. \& Rand, M.J.: Sympathetic postganglionic mechanism. Nature, 184: 163-165, 1959.

4) Burnstock, G.: Comparative studies of purinergic nerves. J. Exp. Zool., 194 : 103-133, 1975.

5) Costa, M. \& Gabella, G.: Adrenergic innervation of the alimentary canal. $Z$. Zellforshc., 122: 357-377, 1971.

6) Devine, C.E. \& Laverty, R.: Fixation for electron microscopy and the retention of ${ }^{3} \mathrm{H}$-noradrenaline by tissues. Experientia, 24 : 1156-1157, 1968.

7) El-Badawi, A. \& Schenk, A.E.: The distribution of cholinergic and adrenergic nerves in the mammalian epididymis a comparative histochemical study. Am. J. Anat., $121:$ 1-13, 1967.

8) Falck, B. \& Hillarp, N.: Fluorescence of catecolamine and related compounds condensed with formaldehyde. Histochem. Cytochem., 10: 384-354, 1973.

9) Gabella, G.: Fine structure of the myenteric plexus in the guinea-pig ileum. J. Anat. (Lond.), $194:$ 13-33, 1968.

10) Hảkansson, R., Larsson, L-I., Nishizaki, H., Owaman, Ch. and Sundler, F.: A new type of formaldehyde-induced fluorescence in a population of endocrine cells in the cat antropyloric mucosa. Histochemie, 34:1-9, 1975.

11) Jones, R.T., Kannan, S.M. \& Daniel, E.E. : Ultrastructural study of guinea pig tracheal smooth muscle and its innervation. Can. J. Pharmacol., 58 : 974-983, 1980.

12) Koelle, B.G.: Current concepts on synaptic structure and function. An. N.Y.A \& S., 183: 5-20, 1971.

13) Nakamura, M., Oda, M., Watanabe, N. \& Tsuchiya, M.: Histochemical, fluorescence and electron microscopic charac. terizations of the autonomic nerves regulating the gastric mucosal microcirculation. Bibl. Anat., $20: 113-119,1981$.

14) Oda, M., Nakamura, M., Watanabe, N., Tsukada, N., Ohya, Y., Sekizuka, E. \& Tsuchiya, M.: Autonomic nervous regulation of gastric mucosal microcirculation-with special reference to the pathogenesis of stress-induced gastric ulcer-. Proceedings of the Tokyo International Symposium on Microcirculation, July, 1981, Tokyo, Japan. Excerpta Medica, Amsterdam, in press.

15) Paton, W.D.H. \& Zar, M.A.: The origin of acetylcholine released from guinea pig intestine and longitudinal muscle strips. J. Physiol. (Lond.), 194 : 13-33, 1963.

16) Read, B.J. \& Burnstock, G.: Adrenergic innervation of the gut musculature in vertebrates. Histochemie, 17: 263-272, 1969.

17) Richardson, B.J. \& Fergasson, C.C.: Neuromuscular structure and function in the airways. Fed. Proc., 38: 202-208, 1979.

18) Slavin, G.B. \& Ballard, W.K.: Morphological studies on the adrenergic innervation of white adipose tissue. Anat. Rec. 191 : 377-389, 1978.

19) Thurreson-Klein, A., Lagercrantz, H. \& Barnard, T.: Chemical sympathectomy of interscapular brown adipose tissue. Acta Physiol. Scand., 98 : 8-18, 1976. 


\section{Explanation of Figures}

\section{Plate I}

Fig. 6. A fluorescence micrograph of the fundic glandular mucosa of the control rat stomach tissue processed by the ALFA method. The linear fluorescence specific for noradrenaline, corresponding to the adrenergic nerve fibers, was found to be abundant in the perivascular plexus of the arterioles (arrow) and some between the gastric epithelial cells in the lamina propria mucosae (double arrow). $\times 2,200$ 
Plate I

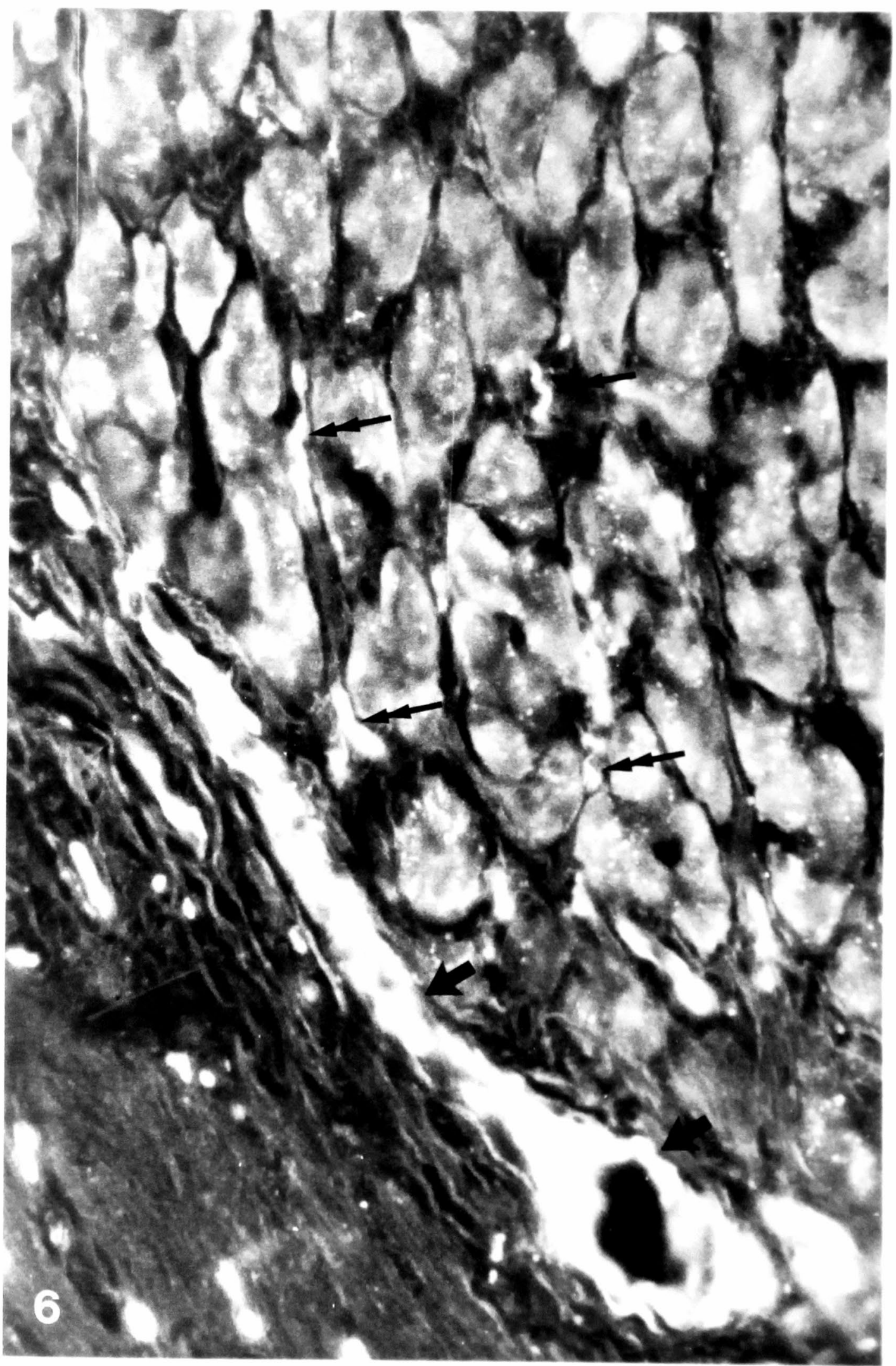




\section{Plate II}

Fig. 7. Fluorescence and light micrographs of the basal one-third of the gastric mucosal layer (lamina propria mucosae) in the rat treated with nialamide and L-Dopa.

a: The fluorescent varicose fibers (arrow) are identical with the adrenergic nerves. They are mainly located arround the arterioles (Ao) in the basal one-third of the rat fundic gland. Few nerves are found around the venules (Ve). Compare with Fig. 7b. ALFA method. $\times 400$

b: The serial sectional of Fig. 7a, stained with hematoxylin-eosin (H \& E). $\times 400$

Fig. 8. In the 6-hydroxydopamine (6-OHDA)-treated rat, the specific fluorescence of noradrenaline is entirely extinguished. ALFA method. $\times 400$ 


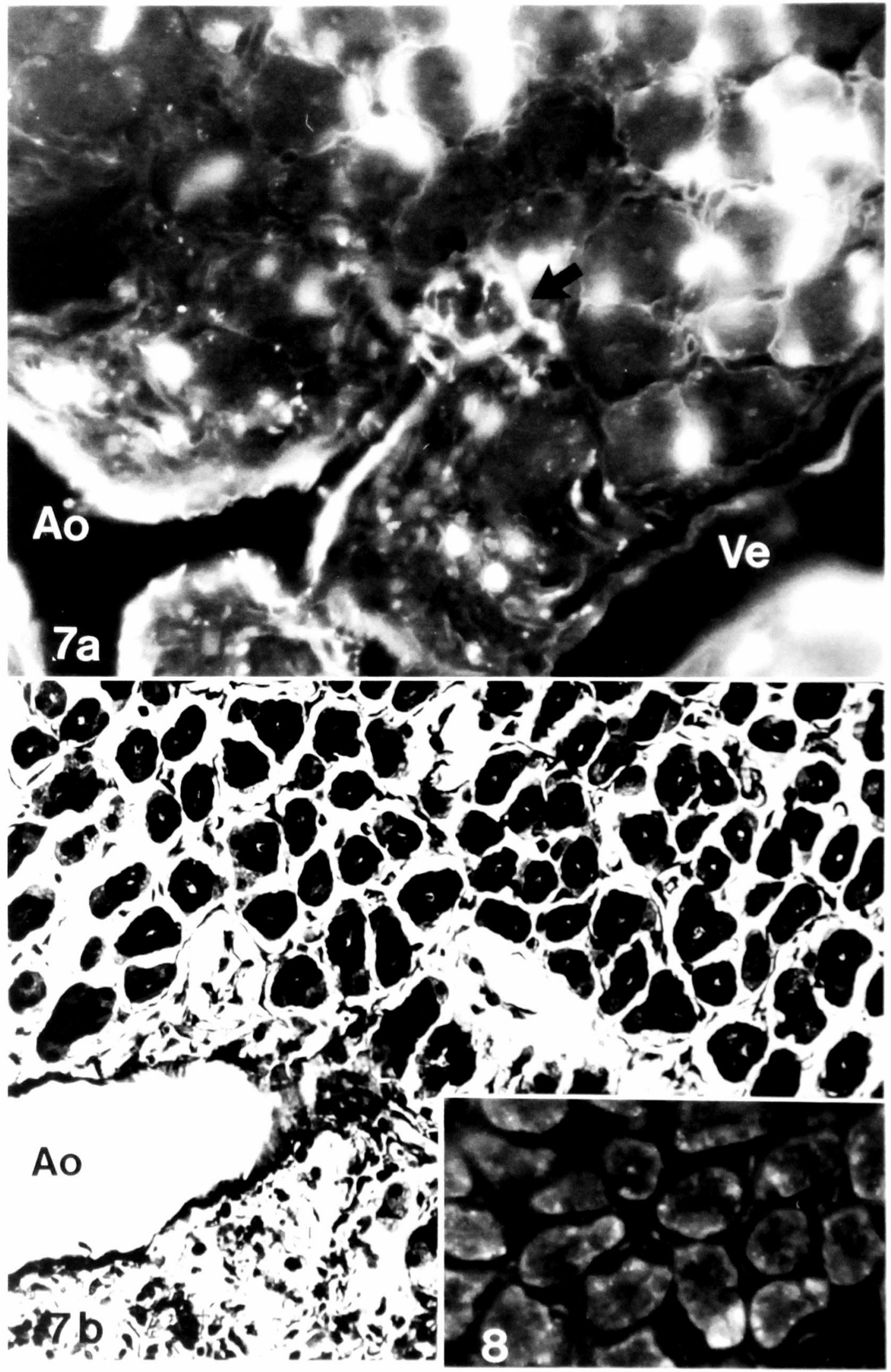

M. Nakamura, et al. 


\section{Plate III}

Fig. 9. Fluorescence and light micrographs of the middle one-third of the gastric mucosal layer in the rat treated with nialamide and L-Dopa.

a: The fluorescent adrenergic fibers are seen in linear fashion between the gastric epithelial cells (arrow). Some fibers surround the capillaries (double arrow). Some epithelial cells are also fluorescent, probably corresponding to the enterochromaffin-like (ECL) cell. The dotted fluorescence is a non-specific one, probably of the chief cell. Compare with Fig. 9-b. $\times 400$

b: The serial section of Fig. 9a, stained with $\mathrm{H} \& \mathrm{E} . \times 400$

Fig. 10. Fluorescence and light micrographs of the upper one-third of the gastric mucosal layer in the rat treated with nialamide and 1-Dopa.

a: The fluorescent nerve fibers are seen only near the gastric epithelial cells (arrow), not around the collecting venules (double arrow). Compare with Fig. 10-b. ALFA method $\times 400$

b: The serial section of Fig. 10a, stained with H \& E. $\times 400$ 
Plate III

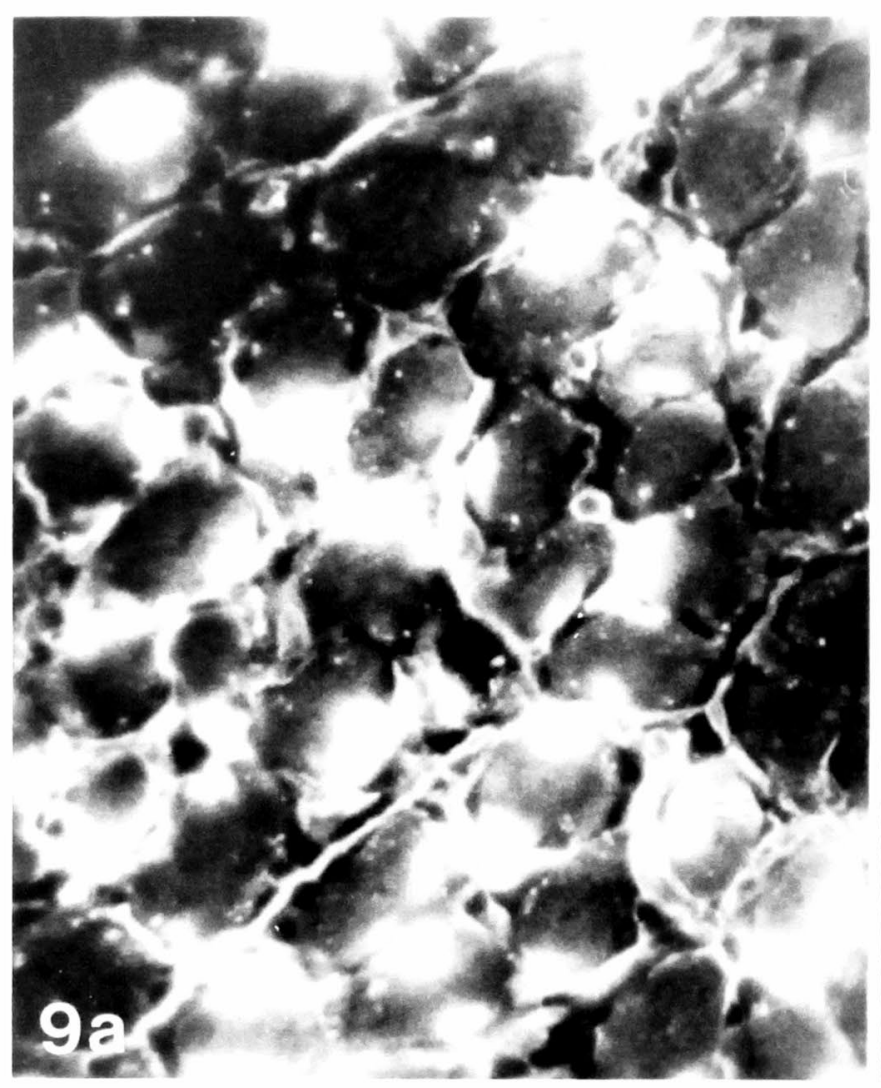

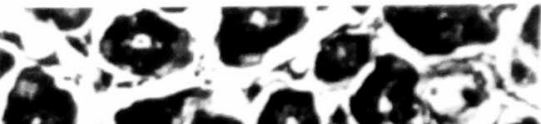

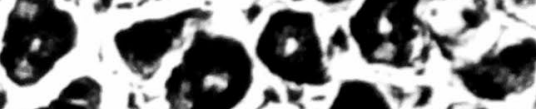

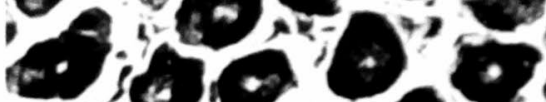
$94:-2+3$

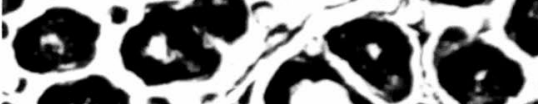

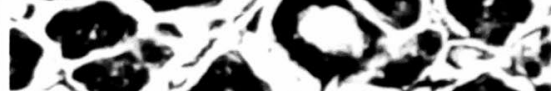
1. *ativet - $450+24$ ? $3^{2}+12+2=1$
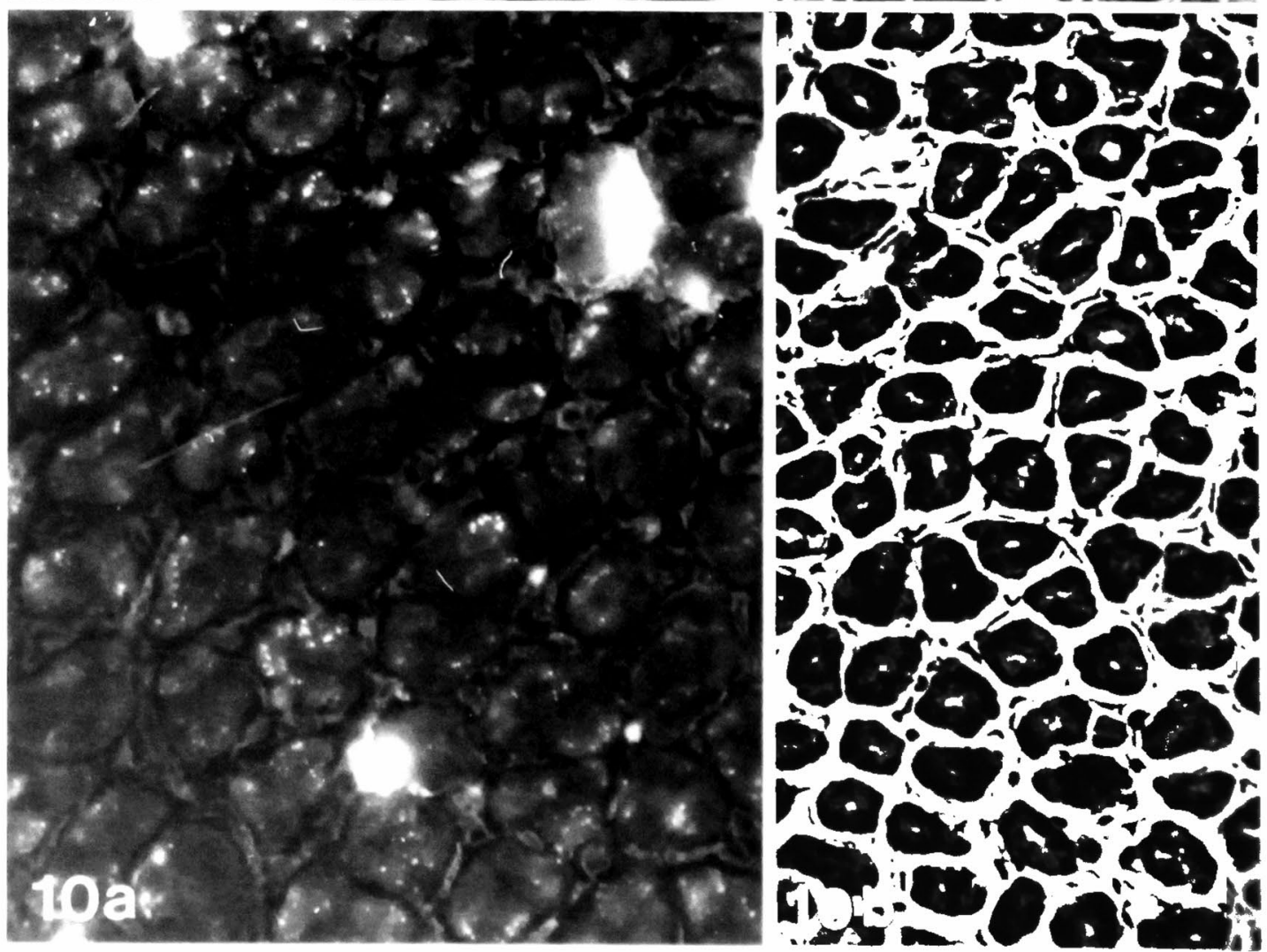

M. Nakamura, et al. 


\section{Plate IV}

Fig. 11. An electron micrograph of the lower one-third of the fundic mucosal layer in the control rat. The nerve bundles comprizing several axons are seen near the true capillary in the lamina propria mucosae. Uranyl acetate and lead citrate stain. $\times 22,000$

Fig. 12. An electron micrograph of the lower one-third of the fundic mucosal layer in the 6-OHDA-treated rat. The nerve endings comprizing both the degenerated adrenergic and the intact cholinergic axons are present near the true capillary at a close distance of $500 \AA$. Uranyl acetate and lead citrate stain. $\times 31,000$

Fig. 13. In the 6-OHDA-treated rat, a gap between the capillary endothelial cells is widened, and the condensed plasma-like substance is noted in the interstitial tissue space around the capillary (arrow), indicating that hypofunction of the peripheral adrenergic nerves is involved in the increased permeability of the capillary vessels in the gastric mucosa. Uranyl acetate and lead citrate stain. $\times 34,000$

Ax: axon, E : capillary endothelium, P: parietal cell 
Plate IV

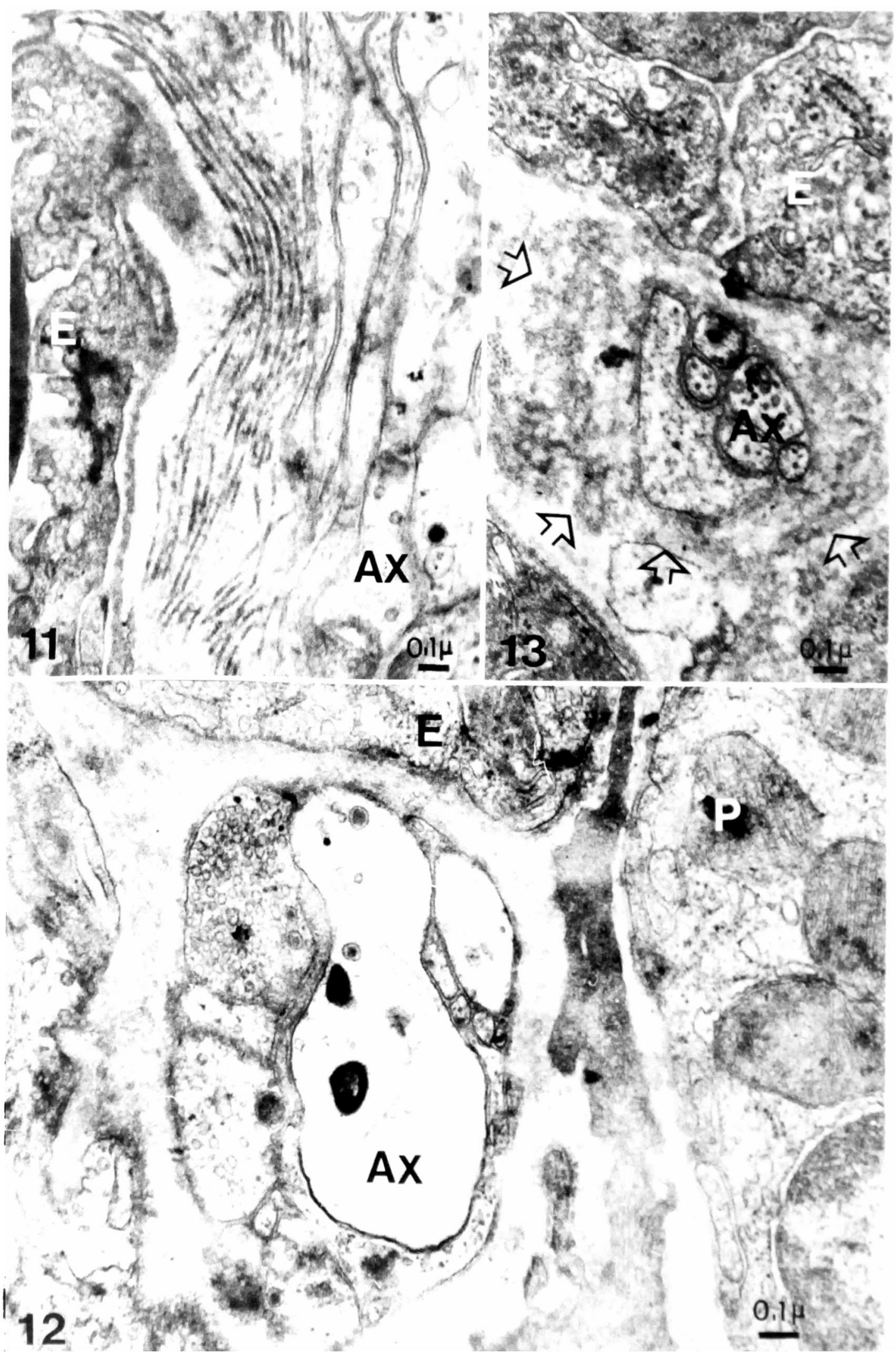

M. Nakamura, et al. 


\section{Plate V}

Fig. 14. The smooth muscle cells (SM) are found between the gastric epithelial cells in the lower one-third of the gastric gland. Note the preterminal axon (arrow) near the smooth muscle cell. P: parietal cell. Uranyl acetate and lead citrate stain. $\times 21,000$

Fig. 15. The nerve terminals are located near the parietal cell, with a short distance of $300 \AA$. The nerve axon is cholinergic in nature. Uranyl acetate and lead citrate stain. $\times 40,000$

Fig. 16. The nerve terminals are also present near the chief cell (C). The interspace between the nerve terminals and the chief cell is larger than that between the nerve terminals and the parietal cells as shown in Fig. 15. Uranyl acetate and lead citrate stain. $\times 38,000$ 


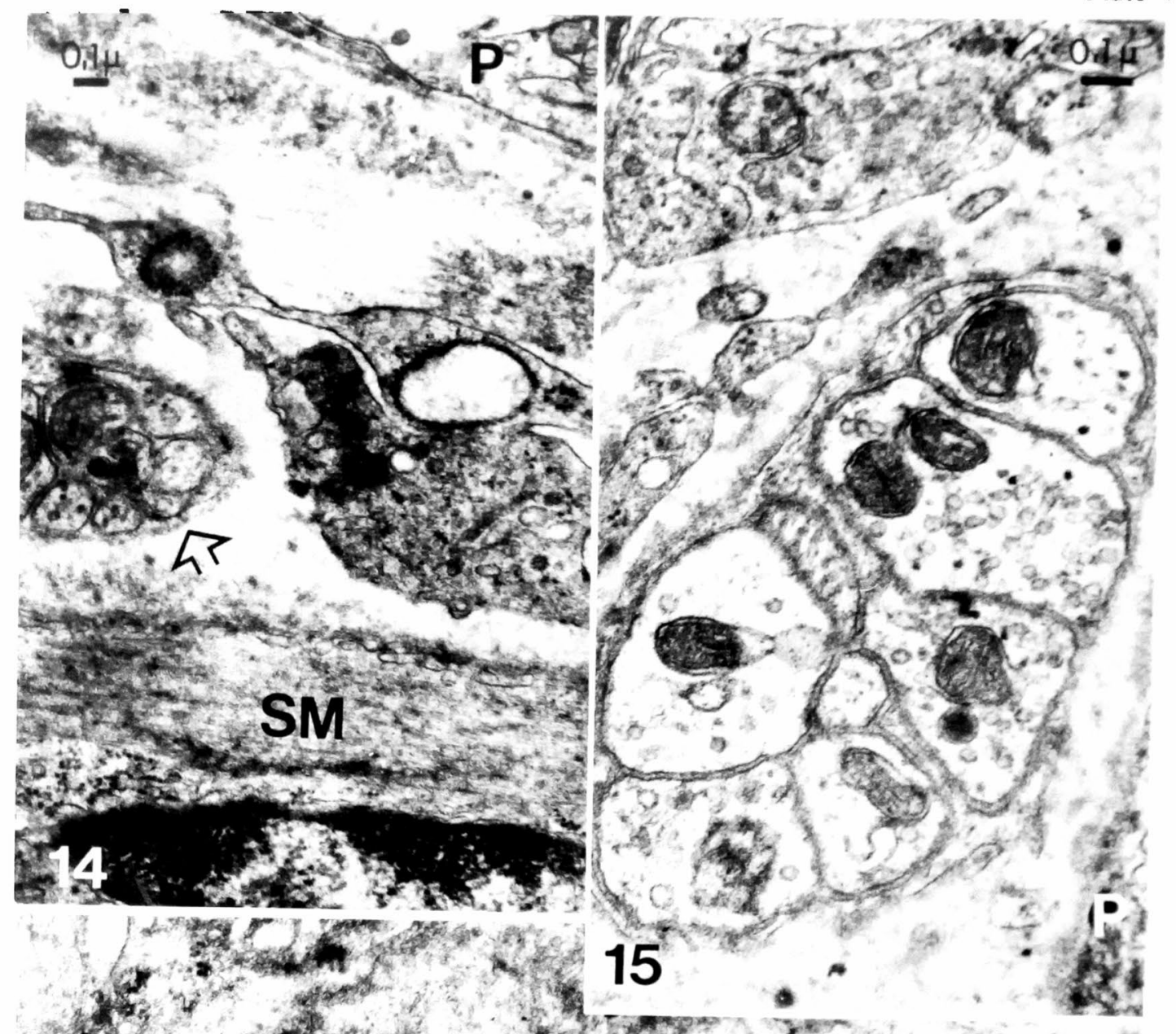

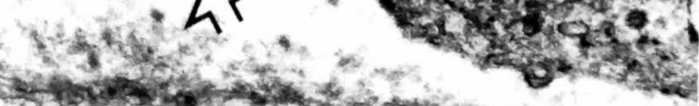

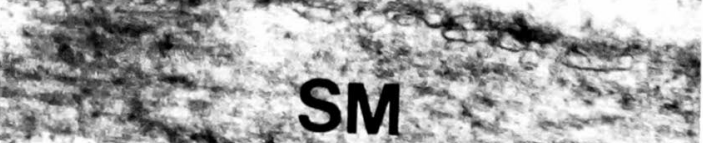

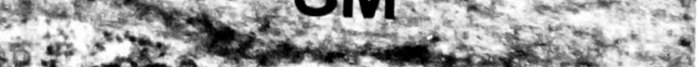

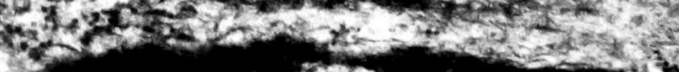

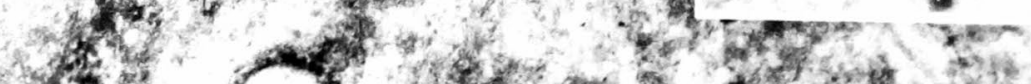

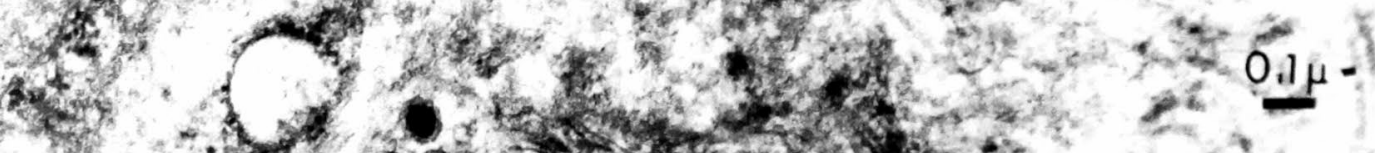

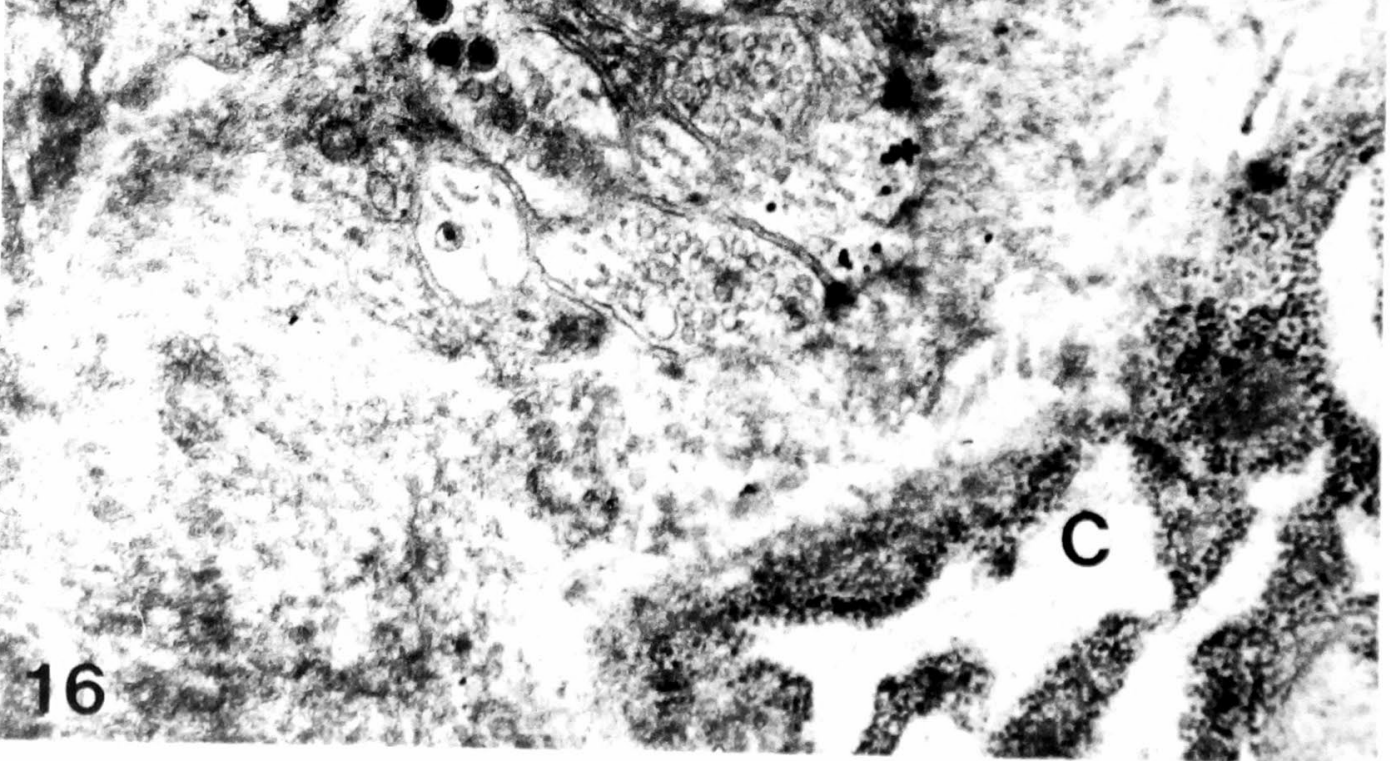

M. Nakamura, et al. 


\section{Plate VI}

Fig. 17. The adrenergic nerves are present between the ECL cell and the true capillary. Uranyl acetate and lead citrate stain. $\times 25,000$

Fig. 18. The nerve axon containing the large electron dense or granulated vesicles found in the basal portion of the fundic gland. This kind of the axon is identical with the purinergic nerve axon, and is found only on occasion. Uranyl acetate and lead citrate stain. $\times 20,000$ Ax: axon, ECL: enterochromaffin-like cell, E: endothelium 
Plate VI

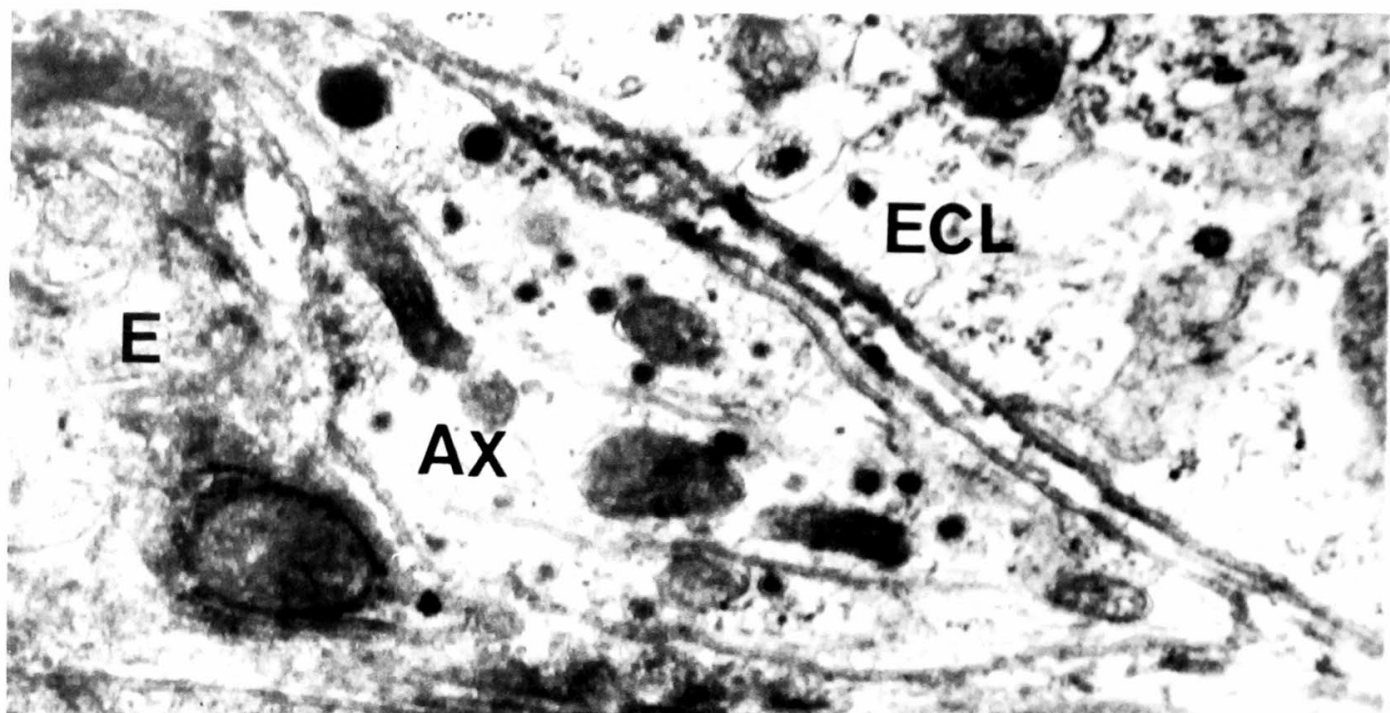

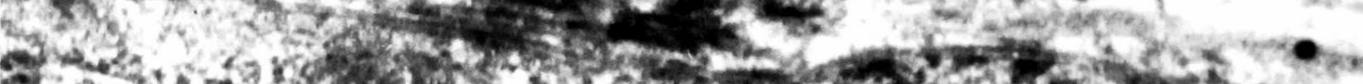

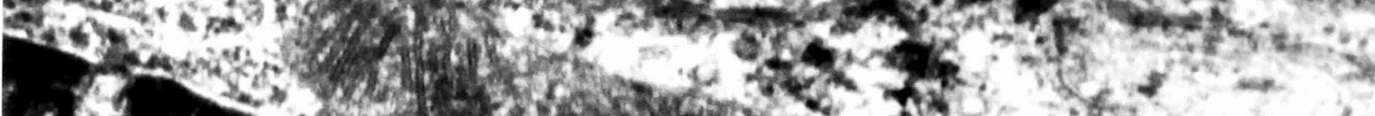

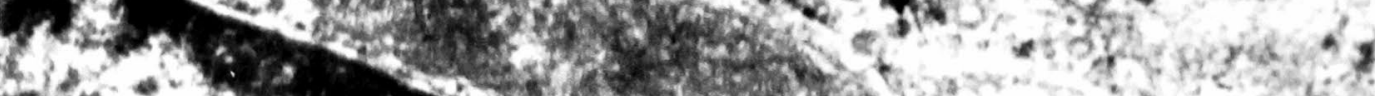

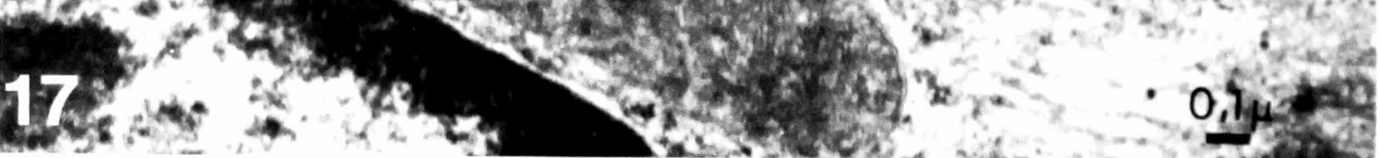

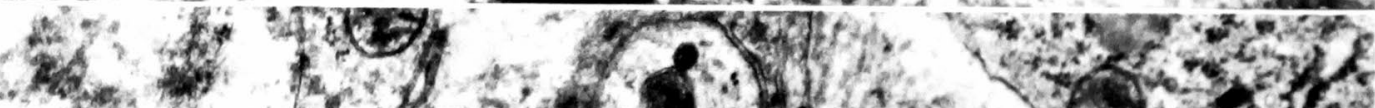

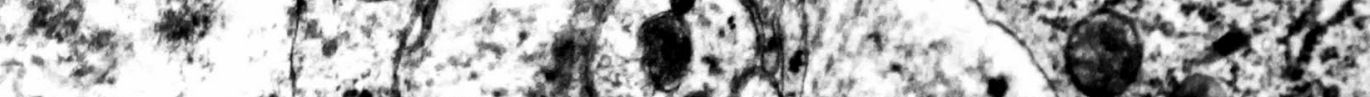

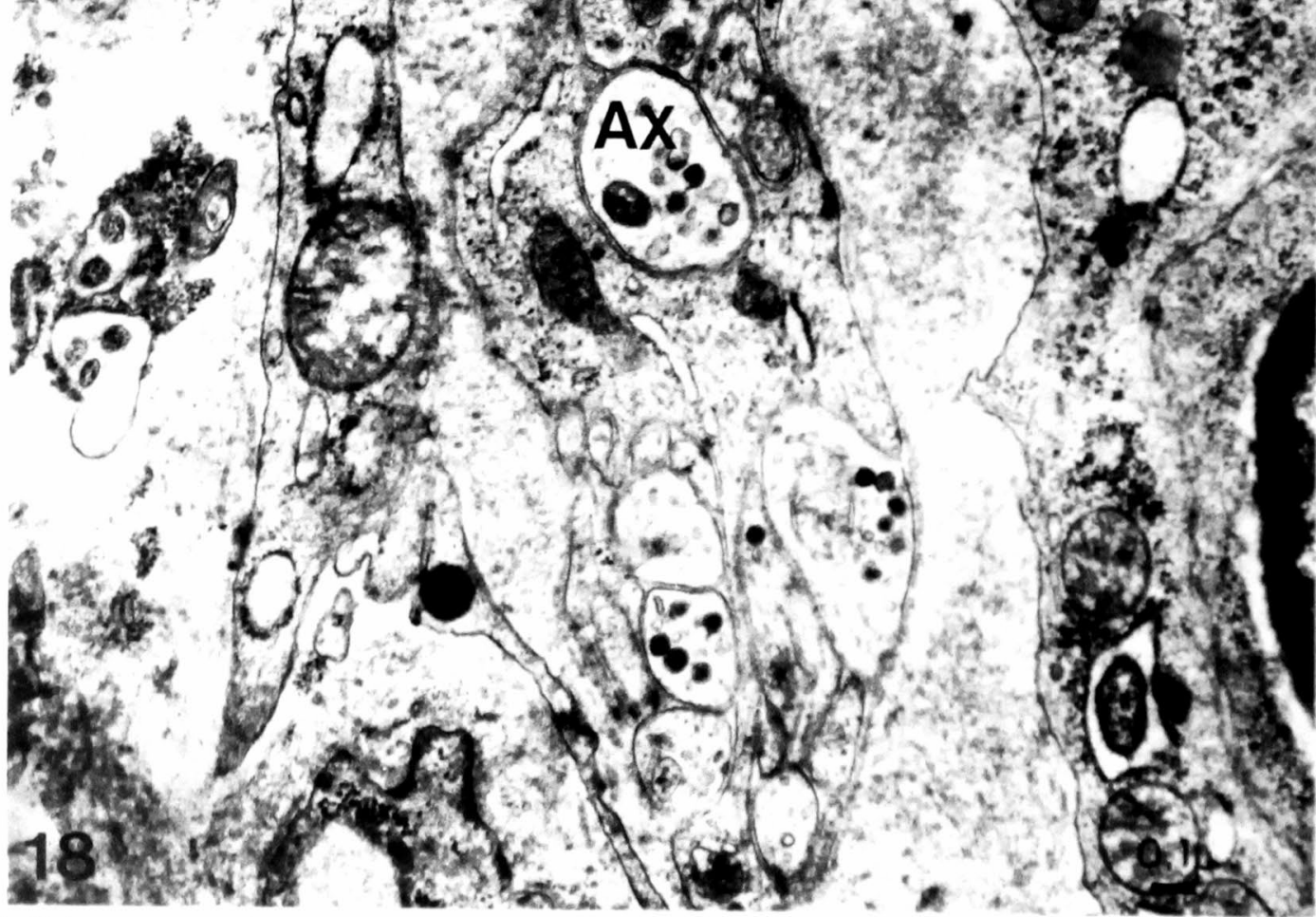

M. Nakamura, et al. 